\title{
Whipple's disease confined to the nervous system
}

\author{
S POLLOCK, PD LEWIS, B KENDALL
}

From the Department of Neurology, Royal Free Hospital, the Department of Histopathology, Royal Postgraduate Medical School, and the Department of Radiology, National Hospital for Nervous Diseases, London

SUMMARY Whipple's disease confined to the nervous system occurred in a 36-year-old woman who presented with grand mal seizures and dementia. There was no evidence of extracerebral involvement and the jejunal biopsy was negative before treatment. Multiple enhancing lesions on CT scan progressed despite therapy with minocycline and prednisone, but resolved on treatment with tetracycline. The dementia did not progress while she was on antibiotic therapy. Whipple's disease should be considered as a treatable cause of progressive dementia even in the absence of an abnormal jejunal biopsy.

In their review of central nervous manifestations in Whipple's disease Pallis and Lewis ${ }^{1}$ pointed out that a variety of neurological manifestations occur, with or without systemic involvement, and that these neurological disorders are treatable. The purpose of the present report is to document a further case of Whipple's disease confined to the nervous system with previously undescribed radiological findings, which responded to therapy.

\section{Case report}

A 36-year-old Irish housewife, presented in December 1977 with two nocturnal grand mal convulsions. She had suffered from intermittent dizziness without vertigo for the previous two years, but had no other symptoms. On admission, she was noted to be vague and apathetic with poor memory for recent events but with no other physical signs. Skull radiograph, gamma scan, ultrasound, and plain computed tomography (CT scan), (fig 1) were normal, but her EEG showed epileptic activity in the right hemisphere. She was discharged on treatment with phenytoin and phenobarbitone. Within four months she was readmitted, having become confused and disorientated in space, with a euphoric mood and further memory loss. She had lost $12 \mathrm{~kg}$ in the previous nine months, but there was no history of steatorrhoea, change in bowel habit, abdominal pain, arthralgia, or fever. On examination there was no hypopigmentation, lymphadenopathy, or abdominal tenderness and no neurological abnormality on formal testing. Psychometric testing confirmed a moderate generalised dementia with an overall IQ of 82 .

Address for reprint requests: Dr SS Pollock, The Middlesex Hospital Medical School, London WIN 8AA, UK.

Received 14 August 1981

Accepted 3 September 1981

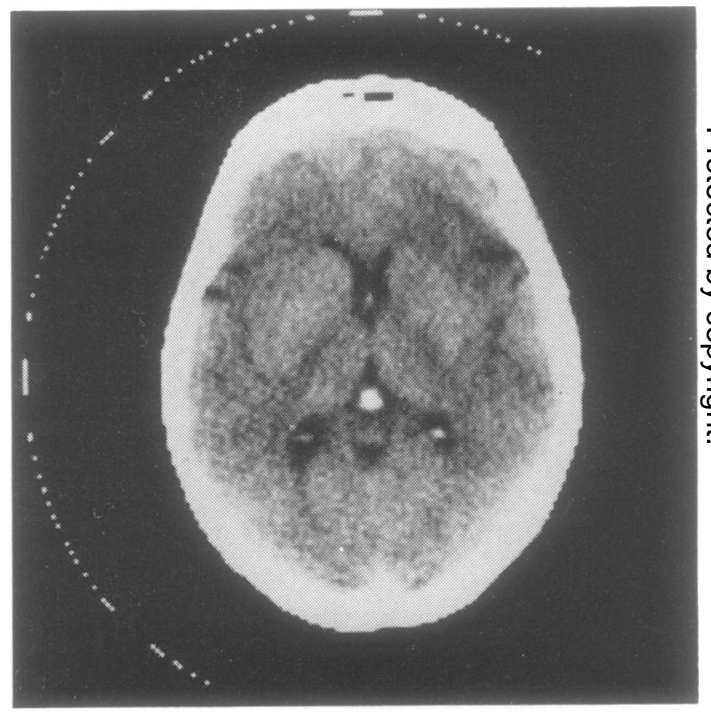

Fig 1 December 1977. Normal plain scan.

\section{Investigations}

ESR $3 \mathrm{~mm} / \mathrm{h}, \mathrm{Hb} 12.9 \mathrm{~g} / \mathrm{dl}$. White cell count $7 \cdot 1 \times 10^{9} / \mathrm{l}$ normal differential. ANF and anti-DNA antibodies were negative. Populations of circulating $\mathrm{T}$ and $\mathrm{B}$ cells were normal, with normal function, and serological tests for fungal antibodies and JC and SMV-40 polyoma viruses were negative. Serum phenytoin and phenobarbitone levels were within the normal range. Faecal fats were normal at $6.3 \mathrm{mmol} /$ day (normal less than $18 \mathrm{mmol} /$ day). The serumfolate was low $(2 \cdot 2 \mu \mathrm{g} / \mathrm{l} ;$ normal $2 \cdot 5 \mu \mathrm{g} / \mathrm{l}-5 \mu \mathrm{g} / \mathrm{l})$. Serum albumin and serum iron levels were normal. The WR was negative in serum and cerebro-spinal fluid. The CSF was examined on three occasions, and the pressure and white 104 

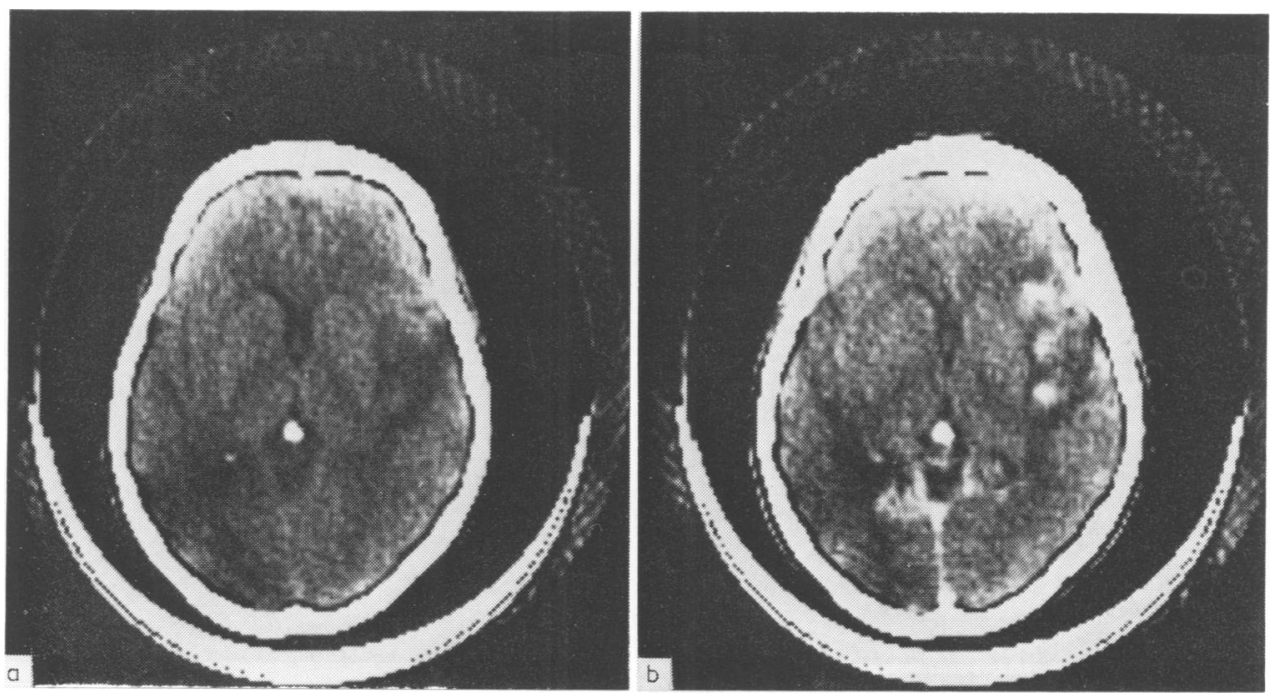

Fig 2 May 1978 (a) plain scan. Lesions of mixed density, below and similar to that of brain are present in both temporal and the left occipital lobes exerting only minimal mass effect. (b) same section after bolus injection of $70 \mathrm{ml}$ Conray 420. There is multifocal enhancement.

cell count were always within normal limits. However, the total protein (normal $0 \cdot 1 \mathrm{~g} / \mathrm{l}-0.4 \mathrm{~g} / \mathrm{l}$ ) rose from $0.45 \mathrm{~g} / \mathrm{l}$ to $0.9 \mathrm{~g} / \mathrm{l}$ in two months prior to treatment, and then fell to $0.45 \mathrm{~g} / \mathrm{l}$ after two months treatment with minocycline. The corresponding IgG fractions (normal less than $10 \%$ of total protein) were $0.093 \mathrm{~g} / \mathrm{l}(20 \cdot 7 \%), 0 \cdot 159 \mathrm{~g} / 1(17 \cdot 7 \%)$ and $0.057 \mathrm{~g} / \mathrm{l}(12.7 \%)$. There was no evidence of sickleparticle-containing cells in the CSF. No fungal antigens could be detected and bacterial (including acid fast) and viral cultures were negative. Jejunal biopsy was normal. A CT scan (fig 2) showed regions of low density involving both temporal lobes with multifocal enhancement and minimal mass effect.

A right temporal craniotomy (Mr Richard Hayward)

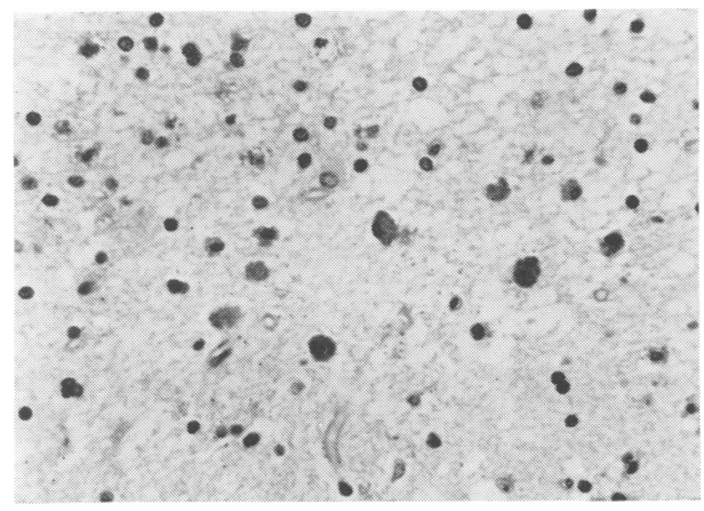

Fig 3 Cerebral biopsy: a zone of rarefaction in the subcortical region shows numbers of large granular, and small PAS-positive cells, together with a protoplasmic astrocyte. Periodic acid-Schiff, $\times 280$. revealed abnormally white and thickened superior and middle temporal gyri. Biopsy through the abnormal brain showed that thickened and gliotic areas were interspersed with soft grey tissue. Histologically there was a subcortical zone $2-3 \mathrm{~mm}$ in diameter of tissue rarefaction with oedema and proliferation of protoplasmic astrocytes, accompanied by numbers of large rounded foamy cells with small dark nuclei and granular cytoplasm staining strongly with PAS. Smaller rounded PAS-positive cells were also present (fig 3). Elsewhere in the biopsy white matter oedema, astrocytic proliferation, and scattered PAS-positive macrophages were seen, and scattered small foci of tissue rarefaction were present in both grey and white matter. No sickle-cell particles or intact bacilli could be detected in formalin-fixed material by electron microscopy.

A presumptive diagnosis of cerebral Whipple's disease was made and the patient was treated with minocycline $100 \mathrm{mg}$ twice daily, and prednisolone $40-60 \mathrm{mg}$ daily for three months, as well as anti-convulsants. Satisfactory minocycline levels were obtained 3 hours after taking the medicine $(1.3 \mu \mathrm{g} /, 1$ serum and $0.54 \mu \mathrm{g} / \mathrm{ml} \mathrm{CSF})$. During this time dementia did not progress and fits did not recur. Repeat psychometic testing showed no significant deterioration, and the EEG improved. However, a repeat CT scan (fig 4) showed increased numbers of enhancing lesions. The antibiotic therapy was changed to tetracycline $250 \mathrm{mg}$ four times a day and because of side effects, prednisolone was reduced to $15 \mathrm{mg} /$ day and stopped completely after three months. Five months after starting this regime, her condition remained static and a further CT scan (fig 5) showed complete resolution of the enhancing lesions but moderate cerebral atrophy. Two years later having taken tetracycline continuously there has been no significant deterioration in her condition although she remains disorientated with short term 

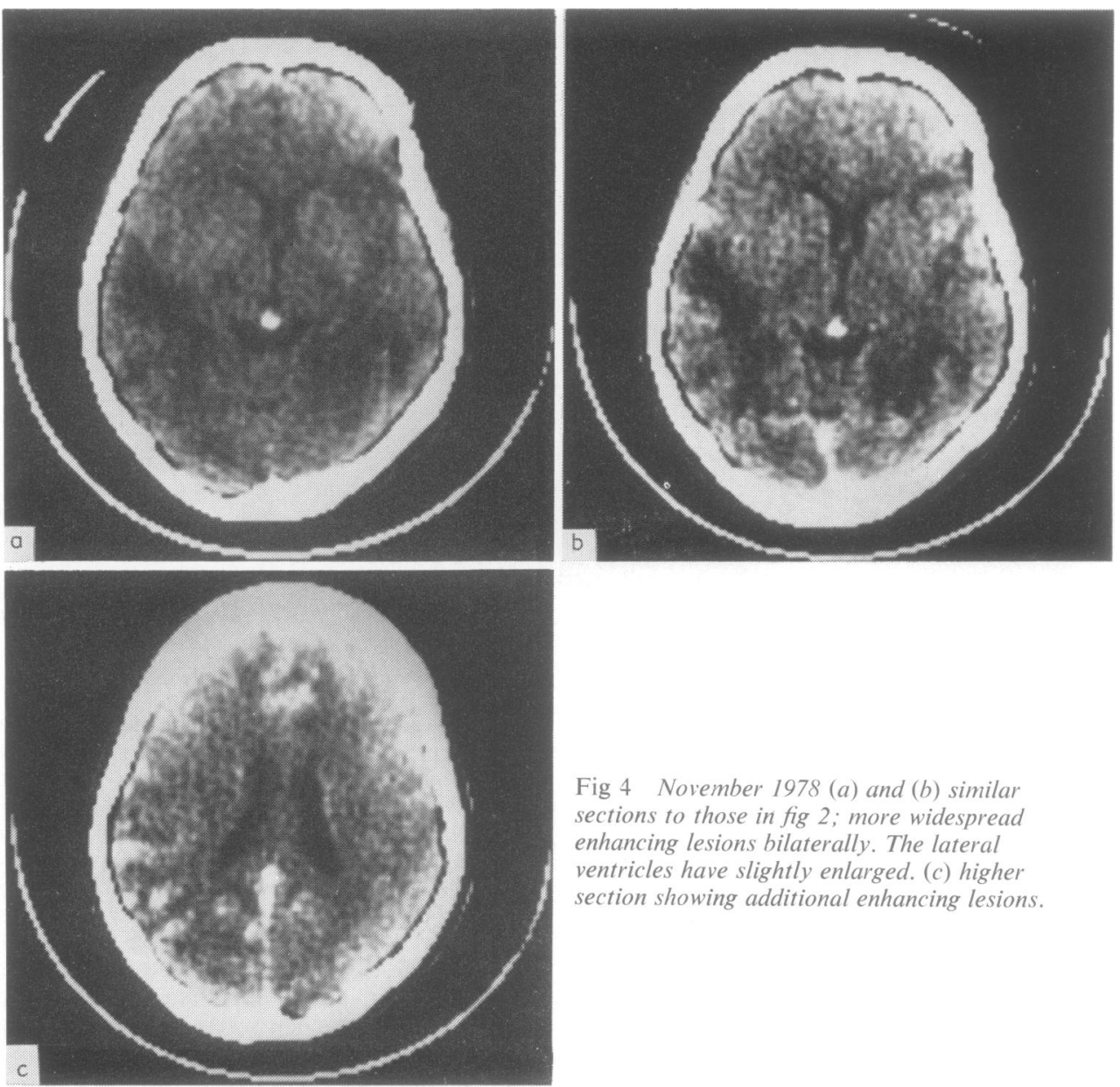

Fig 4 November 1978 (a) and (b) similar sections to those in fig 2; more widespread enhancing lesions bilaterally. The lateral ventricles have slightly enlarged. (c) higher section showing additional enhancing lesions.
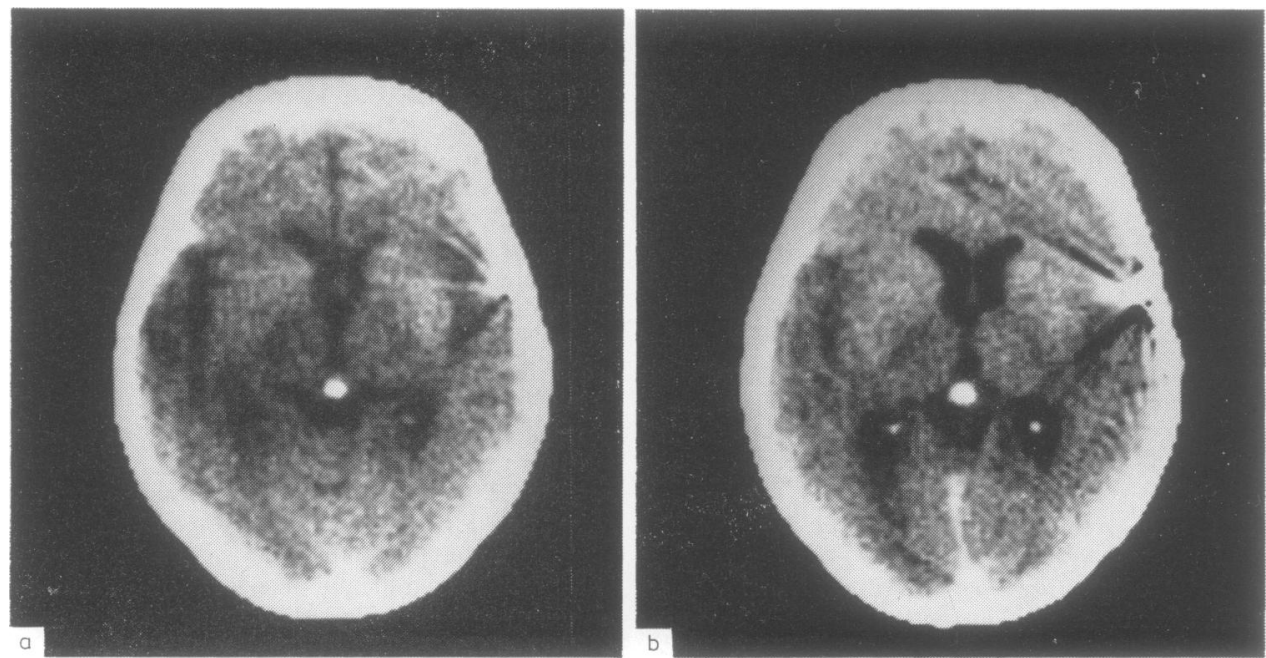

Fig 5 April $1980(a)$ and (b) similar sections to those in figs 2, $4(a)$ and (b). The low density is much less pronounced and there is no longer any abnormal enhancement. The ventricles have enlarged further and there is some widening of the sylvian and interhemispheric fissures owing to moderate cerebral atrophy. 
memory loss and is unable to lead an independent existence.

\section{Discussion}

Since Pallis and Lewis reviewed published cases of Whipple's disease with neurological involvement in $1974,{ }^{2}$ there have been a number of further reports so that by 1980 the same authors ${ }^{1}$ were able to propose that dementia, external ophthalmaplegia and myoclonus of the head, trunk and limbs constituted the central element of the syndrome of neurological involvement in Whipple's disease. Meningitis $^{3}$ and myopathy ${ }^{4}$ have also been documented.

In the present patient, the diagnosis of Whipple's disease was suggested by both clinical and laboratory findings. Dementia in the fourth decade arrested by antibiotic treatment (see below) was strongly suggestive of Whipple's disease. The biopsy findings were also fully consistent with the diagnosis. Failure to demonstrate sickle-particle containing cells first described by Siarecki ${ }^{5}$ or intracellular bacilli in the cortical biopsies from patients with proven Whipple's disease had been noted elsewhere. ${ }^{7}$ The only atypical feature was the patient's sex: only five of 34 cases of Whipple's disease with neurological involvement published up to 1978 were female.

Clinically Whipple's disease may be confined to the nervous system, but even so involvement of the intestines can almost always be shown by biopsy. Absence of histological change in the gut prior to treatment has only once been reported previously. Finelli et $a^{8}$ described two patients with Whipple's disease with predominantly neuro-ophthalmic manifestations and absent gastrointestinal symptoms, one of whom had had a negative jejunal and liver biopsy prior to treatment. The patient of Romanul et $\mathrm{al}^{9}$ had been treated with short courses of steroids and various antibodies over four years, and although at autopsy no gut involvement was demonstrated, no jejunal biopsy was performed prior to treatment or during the course of the illness. In the present case there was no elinical or biochemical evidence of extracranial involvement (the one minimally low serum folate level could have resulted from the concurrent administration of phenytoin). The negative jejunal biopsy prior to therapy confirms that small intestinal biopsy cannot be considered reliable in excluding Whipple's disease in patients with suggestive neurological symptoms.

CT scans in previous reports of central nervous system involvement in Whipple's disease have either been normal ${ }^{1011}$ or revealed cerebral atrophy ${ }^{12}$ only, though in one report ${ }^{13}$ an area of altered density in the right temporo-parietal cortex was also demon- strated. Our series of four EMI scans over 15 months show the evolution of multiple masses of attenuation similar to and lower than that of normal brain which enhanced with intravenous Conray. They exerted minimal mass effect and were associated with progressive cerebral atrophy which persisted following resolution of the lesions on antibiotic therapy. The lesions were widely distributed throughout the cortical and subcortical regions of both cerebral hemispheres, but although brain stem syndromes may be a feature of Whipple's disease, no infratentorial lesions were demonstrated in this case. Similar CT appearances may be seen in sarcoidosis though the basal meninges are usually involved and metastases but no evidence of these diseases was shown on biopsy. The CT scan therefore may prove a useful adjunct in the diagnosis of Whipple's disease of the central nervous system and for following response to treatment. Assessment of the effect of therapy on the neurological consequences of Whipple's disease is not easy because of the slow progression of the disease and the possibility of spontaneous fluctuations. Available reports of the effects of antibiotic treatment on the course of neuro-Whipple's disease are summarised in the table. Patient 1 received tetracycline for only 18 days in the terminal stage of his illness, and in the case described by Schmitt et al, ${ }^{11}$ a patient with gaze palsy, polydipsia, and dementia one month's treatment with iv penicillin and chloramphenicol failed to improve her symptoms significantly. In the remaining cases antibiotics were given from between six months and five years. In these patients gaze palsies and nystagmus were the signs most responsive to treatment, improvement occurring in four out of five patients, and in the remaining case, patient four, treatment with tetracycline was followed by deterioration of the gaze palsy, which was arrested on substitution by chloramphenicol. Dementia was arrested in all five cases and confusional states were improved in three others. Myoclonus improved in two out of four cases, stabilised in one and deteriorated in the fourth despite a change in antibiotic therapy. Papilloedema remitted over one year in the one case where it was observed although steroids were used for the initial two weeks as well as tetracycline.

Hypothalamic syndromes developed despite maintenance treatment with tetracycline or doxycycline in three patients. One patient died, and in the remaining two patients the symptoms persisted despite substitution by chloramphenicol in one case, and chloramphenicol, ampicillin and Septrin in the other. There was only one case of deterioration of neurological symptoms despite prolonged appropriate therapy. In patient 5 right-sided myoclonus progressed on oral penicillin and was not improved by 
Table Response of neurological symptoms in Whipple's disease to antibiotic therapy

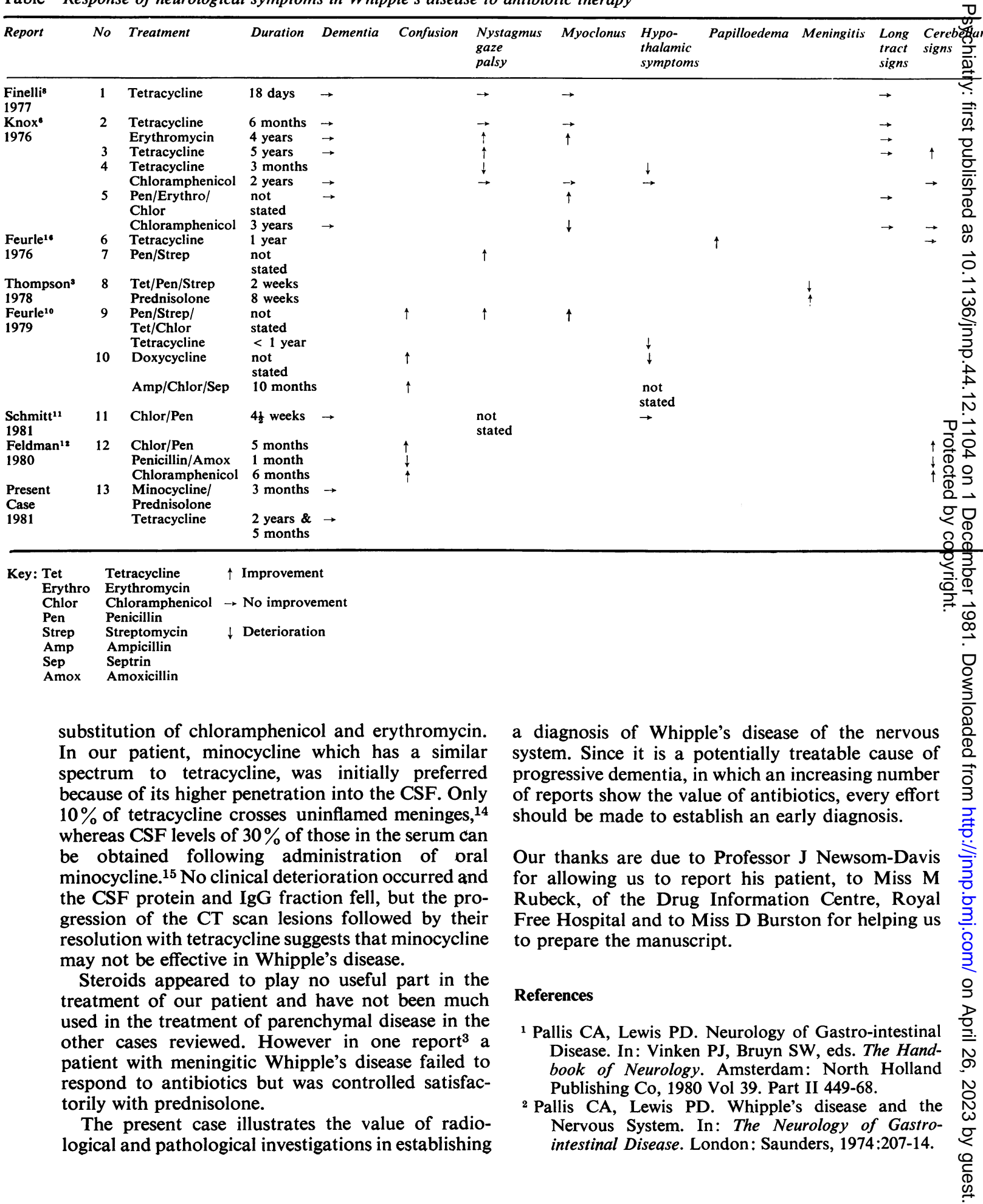


${ }^{3}$ Thompson DG, Ledingham JM, Howard AJ et al. Meningitis in Whipple's Disease. $\mathrm{Br}$ Med J 1978;2: 14-5.

${ }^{4}$ Swash M, Schwartz MS, Vandenburg MJ et al. Myopathy in Whipple's Disease. Gut 1977;18:800-4.

'Siarecki JC, Fine F, Horn RC Jr et al. Central Nervous System involvement in Whipple's disease. $J$ Neuropath Exp Neurol 1960;19:70-5.

${ }^{6}$ Knox DL, Bayless TM, Pittmann FE. Neurologic disease in patients with treated Whipple's disease. Medicine (Baltimore) 1976;55:6:467-76.

7 Powers JM, Rawe SE. A neuropathologic study of Whipple's disease. Acta Neuropathol (Berl) 1979;48: 223-6.

${ }^{8}$ Finelli PF, McEntee WJ, Lesall S et al. Whipple's disease with predominantly neuro-ophthalmic manifestations. Ann Neurol 1977;1:247-52.

${ }^{9}$ Romanul FCA, Radvany J, Rosalis RK. Whipple's disease confined to the brain: a case studied clinically and pathologically. J Neurol Neurosurg Psychiatry 1977;40:901-9.

${ }^{10}$ Feurle GE, Volk B, Waldherr R. Cerebral Whipple's disease with negative jejunal histology. New Engl $J$ Med 1979;300 16:907-8.

${ }^{11}$ Schmitt BP, Richardson H, Smith E et al. Encephalopathy complicating Whipple's disease. Failure to respond to antibiotics. Ann Intern Med 1981;94:51-2.

12 Feldman M, Hendler RS, Morrison EB. Acute meningo-encephalitis after withdrawal of antibiotics in Whipple's disease. Ann Intern Med 1980;93:70911.

${ }^{13}$ Johnson L, Diamond I. Cerebral Whipple's disease. Diagnosis by brain biopsy. Am J Clin Path 1980;74: 486-90.

${ }^{14}$ Kucers A, Bennett NMcK (editors). Tetracyclines. In: The use of antibiotics. 2nd ed. London: Heinmann, $1975: 381-416$.

${ }^{15}$ Shibata K, Hania T, Kato T et al. Laboratory and clinical studies on minocycline in the surgical field. Jap J Antibiotics 1969;22 6:458-62.

${ }^{16}$ Feurle GE, Utz S, Kies D et al. Neurologische Manifestationen des Morbus Whipple. Schweiz Med Wschr 1976;106 47:1642-6. 